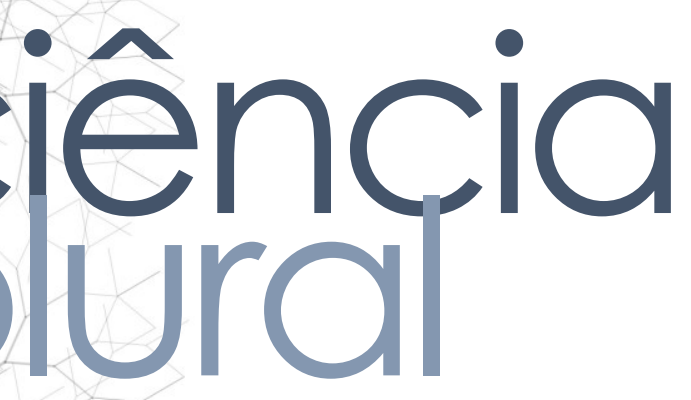

\title{
ATIVIDADE ANTIMICROBIANA DE SUBSTÂNCIAS FITOTERÁPICAS UTILIZADAS NO TRATAMENTO DE AFECÇÕES BUCAIS: ESTUDO IN VITRO
}

Antimicrobian activity of phytoterapic substances used in the treatment of buccal afecctions: In vitro study

Actividad antimicrobiana de sustancias fitoterapéuticas utilizadas en el tratamiento de trastornos orales: estudio in vitro

Gabriel Gomes da Silva • Universidade Federal do Rio Grande do Norte-UFRN • Graduando do Curso de Odontologia da UFRN • E-mail: silvag@gmail.com Júlio Holanda Alves de Souza • UFRN • Graduando do Curso de Odontologia da UFRN・E-mail: juoalso@gmail.com

Abimael Esdras Carvalho de Moura Lira • UFRN • Graduando do Curso de Odontologia da UFRN• E-mail: abimael_esdras@hotmail.com

Luiz Miguel da Rocha Santos • UFRN • Graduando do Curso de Odontologia da UFRN・E-mail: luizsantos2265@gmail.com

Juliana Campos Pinheiro • UFRN • Doutoranda em Ciências Biológicas da UFRN • E-mail: juliana.patologia92@gmail.com

Rafaella Bastos Leite • UFRN • Doutora em Ciências Biológicas pela UFRN •

E-mail: rrafaella_bastos@hotmail.com

Carlos Augusto Galvão Barboza • UFRN • Professor Doutor do Curso de

Odontologia da UFRN • E-mail: carlosaugusto2000@hotmail.com

Maria Regina Macêdo Costa $•$ UFRN - Professora Doutora do Departamento de Odontologia da UFRN • E-mail: mariaregina_costa@hotmail.com

Autora responsável pela correspondência:

Rafaella Bastos Leite • E-mail: rrafaella_bastos@hotmail.com 


\section{RESUMO}

Introdução: A utilização de fitoterápicos para os tratamentos de prevenção e de suporte de patologias situadas nos diversos órgãos e tecidos, caracteriza-se como uma prática amplamente disseminada no Brasil. Objetivo: Avaliar a ação antimicrobiana de 09 substâncias fitoterápicas utilizadas costumeiramente para o tratamento de suporte em algumas afecções bucais no nordeste brasileiro. Materiais: O experimento in vitro foi realizado no Laboratório de Microbiologia do Centro de Biociências da Universidade Federal do Rio Grande do Norte, e o preparo foi realizado por decocção em por um período de 10 minutos e para cada espécie de bactérias, foram utilizadas duas Placas de Petri com meio de cultura Agar Muller Hinton. Métodos: Para a realização da decocção, foi utilizada uma quantidade de 10 gramas e esperou-se os preparos atingir a temperatura ambiente $\left(37^{\circ}\right)$, a atividade antimicrobiana foi avaliada frente à duas cepas de bactérias, através de uma técnica de observação em laboratório, para cada espécie de bactéria. Foram utilizadas duas Placas de Petri com meio de cultura Agar Muller Hinton, onde a inoculação foi realizada por meio de Swabs, e sobre os quais foram realizados cinco poços de aproximadamente $6 \mathrm{~mm}$ de diâmetro. Resultados: Os extratos da semente de manuscada, óleo de coco, casca de cajueiro, semente de sucupira, raiz de urtiga branca e gengibre, foram ineficazes contra o Streptococcus mutans, e Streptococcus mitis, por outro lado o extrato de româ exibiu eficácia para o Streptococcus mutans e a pedra hume exibiu eficácia para o Streptococcus mitis. Conclusões: Os extratos de casca de cajueiro, casca de romã, gengibre e de pedra hume foram eficazes antibacterianos sobre Streptococcus mutans quando comparado com o Periogard $\AA$, considerado padrão ouro nos estudos sobre os agentes antibacterianos na odontologia.

Palavras-Chave: fitoterápicos; odontologia; tratamento farmacológico.

\section{ABSTRACT}

Introduction: The use of herbal medicines for the prevention and support treatments of pathologies located in the various organs and tissues is characterized as a widespread practice in Brazil. Objective: To analyze, from the elaboration of antibiograms of the species Streptococcus mutans and Streptococcus mitis, the antimicrobial activity of phytotherapeutic species in oral disorders. Materials: The in vitro experiment was carried out at the Microbiology Laboratory of the Biosciences Center of the Federal University of Rio Grande do Norte, and the preparation was carried out by decoction in a period of 10 minutes and for each species of bacteria, two plates were used Petri dish with Agar Muller Hinton culture medium. Methods: For the decoction, a quantity of 10 grams was used and the preparations were expected to reach room temperature $\left(37^{\circ}\right)$, the antimicrobial activity was evaluated against two trains of bacteria, using a laboratory observation technique, for each species of acteria, two Petri dishes with Agar Muller Hinton culture medium were used, where inoculation was performed by means of Swabs, and on which five wells of proximately $6 \mathrm{~mm}$ in diameter were made. Results: The extracts of the mamuscada d, coconut oil, cashew bark, sucupira seed, white nettle root and ginger, were fective against Streptococcus mutans, and Streptococcus mitis, on the other hand, megranate extract showed efficacy for Streptococcus mutans and the hume stone 
showed efficacy for Streptococcus mitis. Conclusions: Cashew bark, pomegranate, ginger and hume stone extracts were effective antibacterials against Streptococcus mutans when compared to Periogard $₫$, considered the gold standard in studies on antibacterial agents in dentistry.

Keywords: phytotherapics; odontology; herbal medicine.

\section{RESUMEN}

Introducción: El uso de hierbas medicinales para la prevención y el tratamiento de apoyo de patologías localizadas en los diversos órganos y tejidos se caracteriza como una práctica generalizada en Brasil. Objetivo: analizar, a partir de la elaboración de antibiogramas de las especies Streptococcus mutans y Streptococcus mitis, la actividad antimicrobiana de las especies fitoterapéuticas en los trastornos orales. Materiales: El experimento in vitro se realizó en el Laboratorio de Microbiología del Centro de Biociencias de la Universidad Federal de Rio Grande do Norte, y la preparación se realizó por decocción en un período de 10 minutos y para cada especie de bacteria, se utilizaron dos placas. Placa de Petri con medio de cultivo Agar Muller Hinton. Resultados: los extractos de semilla de mamuscada, aceite de coco, corteza de anacardo, semilla de sucupira, raíz de ortiga blanca y jengibre, no fueron efectivos contra Streptococcus mutans y Streptococcus mitis, por otro lado, el extracto de granada mostró eficacia para Streptococcus mutans y el cálculo de húmero mostraron eficacia para Streptococcus mitis. Métodos: Para la decocción, se utilizó una cantidad de 10 gramos y se esperaba que las preparaciones alcanzaran la temperatura ambiente $\left(37^{\circ}\right)$, se evaluó la actividad antimicrobiana contra dos cepas de bacterias, utilizando una técnica de observación de laboratorio. Para cada especie de bacteria, se utilizaron dos placas de Petri con medio de cultivo Agar Muller Hinton, donde la inoculación se realizó por medio de hisopos, y en la cual se hicieron cinco pozos de aproximadamente $6 \mathrm{~mm}$ de diámetro. Conclusiones: los extractos de corteza de anacardo, granada, jengibre y cálculos de húmero fueron antibacterianos efectivos contra Streptococcus mutans en comparación con Periogard $\AA$, considerado el estándar de oro en estudios sobre agentes antibacterianos en odontología.

Palabras clave: fitoterápicos; odontología; medicina herbaria. 


\section{Introdução}

O Brasil é considerado, um dos poucos países com extremo potencial de produção de fitoterápicos, em larga escala, para a indústria farmacêutica, posto que possua uma quantidade incomensurável de vegetais com propriedades medicinais ${ }^{1}$. Ressalta-se ainda, que esse país possui aproximadamente um terço da flora mundial, cuja representação desses biótipos ocorre nos cinco biomas brasileiros. Contudo, evidencia-se que a utilização de fitomedicamentos ainda não faz parte da realidade nacional, inclusive no próprio Sistema Único de Saúde - SUS².

No Brasil, a política com fitoterápicos remota de 1981 por meio da Portaria $\mathrm{n}^{\circ}$ 212 de 11 de setembro, do Ministério da Saúde, que veio ao longo dessa trajetória, implementando várias medidas que envolvem plantas medicinais, com grande destaque para a portaria interministerial 2960, de 09 de dezembro de 2008, e a portaria 971, de 03 de maio de 2006, que insere as práticas integrativas e complementares no Sistema Único de Saúde - SUS². O uso de fitoterápicos, pelos profissionais da odontologia, somente foi reconhecido e regulamentado como prática integrativa e complementar à saúde bucal pelo Conselho Federal de Odontologia, em 19 de novembro de 2008, por meio da Resolução no 082/2008 - $\mathrm{CFO}^{3}$.

O crescimento mundial da fitoterapia entre os programas preventivos e curativos tem estimulado a avaliação dos extratos de plantas para o uso na odontologia com ação antibacteriana, anti-inflamatória, anti-hemorrágica e anestésica. Entretanto, o uso popular pode sugerir espécies potencialmente importantes, porém, faz-se necessário uma série de estudos, entre eles, a identificação de espécies com comprovada ação farmacológica e/ou substâncias biologicamente ${ }^{4}$. Este estudo tem como objetivo, avaliar a ação antimicrobiana de 09 substâncias fitoterápicas utilizadas costumeiramente para o tratamento de suporte em algumas afecções bucais no nordeste brasileiro.

\section{lateriais}

Através de experimentos in vitro, foram analisadas as propriedades anticrobianas da semente de manuscada, caule de cajueiro, óleo de coco, casca de romã, 
pedra hume, sementes de sucupira, raízes de urtiga branca, casca do juazeiro e gengibre. Os fitoterápicos foram obtidos em bancas de feira livre oriundos da cidade de Natal-RN, Brasil, e o preparo foi realizado por decocção por um período de 10 minutos, exceto o óleo de coco, que foi adquirido sob a forma de extrato.

Quadro 01: Fitoterápicos utilizados nas afecções bucais e devidas formas de preparo. Natal-RN, Brasil, 2019.

\begin{tabular}{|c|c|}
\hline PRODUTO & PREPARO \\
\hline Semente de manuscada & Decocção \\
\hline Casca de juazeiro & Decocção \\
\hline Óleo de coco & Extrato \\
\hline Casca de cajueiro & Decocção \\
\hline Casca de romã & Decoç̧ão \\
\hline Pedra Hume & Decocção \\
\hline Semente de sucupira & Decocção \\
\hline Gengibre & Decocção \\
\hline Raiz de urtiga branca & Decocção \\
\hline
\end{tabular}

\section{Métodos}

Para a realização da decocção, foi utilizada uma quantidade de 10 gramas e esperou-se os preparos atingir a temperatura ambiente $\left(37^{\circ}\right)$, a qual foi verificada com o auxílio de um termômetro até serem condicionados em tubos de centrifugação tipo Falcon, estéreis, e serem refrigerados, a uma temperatura entre $2^{\circ} \mathrm{C}$ e $6^{\circ} \mathrm{C}$ por um período de 24 horas. O quadro 01 especifica as respectivas formas de preparo das substâncias fitoterápicas.

Foi realizada a elaboração de antibiogramas com as espécies Streptococcus mutans e Streptococcus mitis no Laboratório de Microbiologia, do Centro de Biociências Universidade Federal do Rio Grande do Norte, e as escolhas dessas espécies acterianas foram devido ao fato das mesmas apresentarem grande influência na esença da cárie e de interferirem na colonização por espécies bucais patogênicas olvidas em doenças como a cárie e doença periodontal. A atividade antimicrobiana 
foi avaliada frente à duas cepas de bactérias, o Streptococcus mutans (ATCC 25175) e Streptococcus mitis (ATCC 98811) através de uma técnica de observação em laboratório. A solução de gluconato de clorexidina na concentração de $0,12 \%$ (Periogard $\AA$. ColgatePalmolive Ind. Com. São Paulo - SP, Brasil) foi utilizado como controle.

As cepas previamente preparadas foram suspensas em solução salina, até que atingisse uma concentração próxima a 1,5 x $108 \mathrm{cel} / \mathrm{ml}$, com um turvamento similar ao tubo \#0,5 da escala de McFarland. Para cada espécie de bactérias, foram utilizadas duas Placas de Petri com meio de cultura Agar Muller Hinton, onde a inoculação foi realizada por meio de Swabs, e sobre os quais foram realizados cinco poços de aproximadamente $6 \mathrm{~mm}$ de diâmetro. Em cada poço foi inserido 0,8 mm de substância correspondente a cada fitoterápico. O teste foi realizado em duplicata, para cada espécie havia uma placa usada como o controle positivo, somando ao total de oito Placas de Petri, que foram encubadas posteriormente em estufas a $37^{\circ} \mathrm{C}$, por $24 \mathrm{~h}$.

As Placas de Petri semeadas com Streptococcus mitis foram marcadas como MIT1 e MIT-2 e as que foram semeadas com Streptococcus mutans foram marcadas como MUT-1 e MUT-2. As duplicatas foram marcadas como MIT-3 e MIT-4 para semeadas com Streptococcus mitis e MUT-3 e MUT-4 para as que foram semeadas com Streptococcus mutans. Os poços foram numerados de um a nove em algarismos romanos e com a letra " $C$ " ficou representado o controle, de acordo com o quadro 02.

Quadro 02. Identificação dos extratos naturais e placa de Petri. Natal-RN, Brasil, 2019.

\begin{tabular}{|c|c|}
\hline ALGARISMO & EXTRATO \\
\hline I & Semente de manuscada \\
\hline II & Casca de cajueiro \\
\hline III & Óleo de coco \\
\hline IV & Casca de juazeiro \\
\hline V & Casca de romã \\
\hline VI & Semente de sucupira \\
\hline VII & Raiz de urtiga branca \\
\hline VIII & Gengibre \\
\hline IX & Pedra hume \\
\hline C & Periogard ${ }^{\circledR}$ - Controle \\
\hline
\end{tabular}


Após a identificação prévia de cada uma das substâncias a partir da utilização dos algarismos romanos, procedeu-se a verificação, com a consequente medição de cada um dos halos de inibição desenvolvidos pelos extratos, com a utilização de paquímetro, milimetricamente. Para as medições dos halos de inibição, não houve ponto de corte para a definição de atividade antimicrobiana quanto ao tamanho do halo.

\section{Resultados e Discussão}

Os resultados obtidos pelos diferentes extratos, frente às cepas de Streptococcus mutans e Streptococcus mitis são apresentados na tabela 01 e tabela 02.

Tabela 01. Resultado dos extratos frente à cepa Streptococcus mutans. Natal-RN, Brasil, 2019.

\begin{tabular}{|c|c|c|c|c|}
\hline EXTRATO & MUT - 1 & MUT - 2 & MUT - 3 & MUT - 4 \\
\hline Semente de manuscada & $\begin{array}{c}\text { Sem } \\
\text { inibição }\end{array}$ & $\begin{array}{c}\text { Sem } \\
\text { inibição }\end{array}$ & & \\
\hline Casca de cajueiro & $8 \mathrm{~mm}$ & $20 \mathrm{~mm}$ & & \\
\hline Óleo de coco & $\begin{array}{c}\text { Sem } \\
\text { inibição }\end{array}$ & $\begin{array}{c}\text { Sem } \\
\text { inibição }\end{array}$ & & \\
\hline Casca de juazeiro & $\begin{array}{c}\text { Sem } \\
\text { inibição }\end{array}$ & $\begin{array}{c}\text { Sem } \\
\text { inibição }\end{array}$ & & \\
\hline Casca de romã & $25 \mathrm{~mm}$ & $30 \mathrm{~mm}$ & & \\
\hline Semente de sucupira & & & Contaminado & $\begin{array}{c}\text { Sem } \\
\text { inibição }\end{array}$ \\
\hline Raiz de urtiga branca & & & Contaminado & $\begin{array}{c}\text { Sem } \\
\text { inibição }\end{array}$ \\
\hline Gengibre & & & Contaminado & $20 \mathrm{~mm}$ \\
\hline Pedra hume & & & Contaminado & $25 \mathrm{~mm}$ \\
\hline Periogard $^{\circledR}$ & & & Contaminado & $35 \mathrm{~mm}$ \\
\hline
\end{tabular}


Tabela 02. Resultado dos extratos frente à cepa streptococcus mitis. Natal-RN, Brasil, 2019.

\begin{tabular}{c|c|c|c|c}
\hline EXTRATO & MIT - 1 & MIT - 2 & MIT - 3 & MIT -4 \\
\hline Semente de manuscada & Contaminado & Contaminado & & \\
\hline Casca de cajueiro & Contaminado & Contaminado & & \\
\hline Óleo de coco & Contaminado & Contaminado & & \\
\hline Casca de juazeiro & Contaminado & Contaminado & & \\
\hline Casca de romã & $18 \mathrm{~mm}$ & $15 \mathrm{~mm}$ & & \\
\hline Semente de sucupira & & & Sem inibição & Sem inibição \\
\hline Raiz de urtiga branca & & & Sem inibição & Sem inibição \\
\hline Gengibre & & & Sem inibição & Sem inibição \\
\hline Pedra hume & & & $20 \mathrm{~mm}$ & 20 mm \\
\hline Periogard & & & $30 \mathrm{~mm}$ & Contaminado \\
\hline
\end{tabular}

A análise feita dessas amostras pode nos evidenciar a ineficácia da semente de manuscada na inibição do crescimento do Streptococcus mutans, tendo em vista a ausência de um halo de inibição. O cajueiro apresentou um pequeno halo de inibição contra o crescimento bacteriano, em torno de $8 \mathrm{~mm}$ e $20 \mathrm{~mm}$ com uma definição disforme de diâmetro. O óleo de coco não apresentou halo de inibição frente ao cultivo bacteriano, além de apresentar contaminação por crescimento de fungos. O extrato da casca do juazeiro não apresentou halo de inibição ao Streptococcus mutans. O extrato de romã apresentou um halo de inibição de $25 \mathrm{~mm}$ e $30 \mathrm{~mm}$, impedindo o desenvolvimento da bactéria Streptococcus mutans. A semente de sucupira, a raiz da urtiga branca e o gengibre não obtiveram halos de inibição. A pedra hume obteve um halo de inibição para Streptococcus mitis com cerca de $20 \mathrm{~mm}$ disforme. E o grupo controle obteve um halo de $30 \mathrm{~mm}$ bem definido.

Os resultados obtidos pelo extrato da casca do cajueiro podem estar relacionados com alguma fração do ácido anacárdico contido em sua casca, uma vez que estudos realizados por Indu et al. (2006) ${ }^{5}$ relatam a ação antibacteriana sobre Streptococcus mutans por esse ácido, entretanto, estudos realizados por Freitas et $(2007)^{6}, 90 \%$ dessa substância é extraída da casca da castanha do caju, em uma ncentração que apresenta propriedades cáusticas e irritantes ${ }^{7}$, mas que nos dúnculos do caju também apresenta esse composto em baixa proporção ${ }^{8}$ contudo, 
não foi encontrado literatura que de fato afirme a presença de ácido anacárdico em outras partes do vegetal, para afim de comparação com esse estudo.

Os estudos realizados por Levy et al. (2006) ${ }^{9}$, corroboram com os resultados obtidos pelo extrato da casca de romã, pois foi observado em uma pesquisa in vitro que Streptococcus mutans e Streptococcus mitis possuem sensibilidade a esse fitoterápico, apresentando halos de inibição de até $20 \mathrm{~mm}^{10}$. A ação antimicrobiana da romã é composta por taninos (substâncias polifenólicas) e alcaloides que agem sobre os microrganismos ${ }^{11}$.

Os resultados obtidos na placa MUT- 3 apontam para um possível erro de técnica durante a preparação da placa, visto que sua duplicata, a placa MUT- 4 apresentou resultados positivos quanto ao crescimento bacteriano e as ações dos extratos foram visíveis, quanto a sua eficácia ou não.

Não foram encontrados estudos que correlatam a atividade antimicrobiana contra Streptococcus mutans e streptococcus mitis, do extrato da semente de sucupira. Estudos realizados por Ferreira et al. (2014) ${ }^{11}$ chegaram à conclusão de que o extrato da semente de sucupira não apresenta atividade antimicrobiana frente as cepas de streptococcus aureus, Pseudomonas aeruginosa e Escherichia coli, porém, no estudo realizado por Silva et al. (2008) ${ }^{12}$ houve halo de inibição de crescimento contra fitobactérias especificamente Clavibacter michiganensis subsp. michiganensis, Xhantomonas campestris pv. Campestris e Pseudomonas syringae. O extrato da semente de sucupira não apresentou halo de inibição sobre Streptococcus mutans, mas não foi encontrado estudos semelhantes para fins de comparação.

O extrato da raiz de urtiga branca não apresentou efeito sobre Streptococcus mutans, e não foram encontrados registros literários sobre alguma ação antibacteriana desse fitoterápico. O extrato de gengibre apresentou halo de inibição sobre o crescimento de colônia de Streptococcus mutans, de $20 \mathrm{~mm}$, de acordo com estudos realizados por Cutrim et al. (2019) ${ }^{13}$ relata que o gengibre tem ação bactericida e acteriostático. A falta de uma padronização de preparação do extrato de gengibre de levar a variação de resultados, uma vez que os componentes do gengibre são nolábeis ${ }^{14}$. Os resultados da ação antimicrobiana pelo extrato de pedra hume 
mostraram-se eficazes tanto contra cepas de Streptococcus mutans e streptococcus mitis, contudo, não foi encontrado na literatura estudo similar, segundo Silva et al. (2014) ${ }^{15}$ não existe literatura cientifica sobre o estudo da pedra hume na odontologia.

Os extratos da semente de manuscada, óleo de coco, casca de cajueiro, semente de sucupira, raiz de urtiga branca e gengibre, foram ineficazes contra o Streptococcus mutans, e Streptococcus mitis, por outro lado o extrato de romã exibiu eficácia para o Streptococcus mutans e a pedra hume exibiu eficácia para o Streptococcus mitis.

Como limitação do estudo, foi possível constatar a contaminação da placa MUT3, porém essa contaminação não prejudicou na interpretação dos resultados.

\section{Conclusões}

De acordo com os resultados encontrados no estudo, pode-se concluir que dos nove extratos utilizados, apenas a casca de romã e pedra hume tiveram atividade antimicrobiana para Streptococcus mutans, e Streptococcus mitis, enquanto a casca de cajueiro apresentou atividade somente para o Streptococcus mutans e o gengibre somente para o Streptococcus mitis. Além disso, acredita-se que para resultados mais completos deve-se levar em consideração a aplicação dos extratos dessas substâncias fitoterápicas em outras cepas bacterianas possíveis. Ora para confirmar a possível ação antimicrobiana ou mesmo para refutar a corriqueira prática de suas utilizações na medicina caseira no tratamento de afecções bucais.

\section{Referências}

1. Sasada INV, Munerato MC, Gregianin LJ. Mucosite oral em crianças com câncer Revisão de literatura. RFO, Passo Fundo. 2013;18(3):345-50.

2.Brasil. Agência Nacional de Vigilância Sanitária. Formulário de Fitoterápicos da armacopéia Brasileira / Agência Nacional de Vigilância Sanitária. v. 1. Brasília: nvisa, 2011.

vangelista SS, Sampaio FC, Parente RC, Bandeira MFC. L- Fitoterápicos na ontologia: estudo etnobotânico na cidade de Manaus. Rev. Bras. Pl. Med. 2013; 15(4): $-519$. 
4. Halibi, MF, Sheikh BY. Anti-Proliferative Effect and Phytochemical Analysis of Cymbopogon citratus Extract. BioMed Research International. 2014.

5. Salehi R, Savabi O, Kazemi M, Kamali S, Salehi AR, Eslami G, Tahmourespour A. Effects of Lactobacillus reuteriderived biosurfacectnt on the gene expression profile of essential adhesion genes ( $\mathrm{gtfB} \mathrm{gtfC}$ and $\mathrm{ftf}$ ) of Streptococcus mutans. Advanced Biomedical Research. 2014; 3:169.

6.Christopher EE, Akpan E, Nyoh A. Ethnopharmacology, phytochemistry and biological activities of Cymbopogon citratus (DC.) Stapf extract [J]. Chinese Journal of Natural Medicines. 2015; 13(5):321-337.

7.Machado AC, Oliveira RC. Medicamentos Fitoterápicos na odontologia: evidências e perspectivas sobre o uso da aroeira-do-sertão (Myracrodruon urundeuva Allemão). Rev. Bras. Pl. Med. 2014; 16(2): 283-289.

8. Thabit RAS, Cheng XR, Tang X, Sun J, Shi YH, Le GW. Antioxidant and antibacterial activities of extracts from Conyza bonariensis growing in Yemen. Pakistan jornal of pharmaceutical sciences. 2015; 28(1):129.

9. Trotti A, Bellm LA, Epstein JB, Frame D, Fuchs HJ, Gwede CK, Komaroff E, Nalysnyk L, Zilberberg MD. Mucositis incidence, severity and associated outcomes in patients with head and neck cancer receiving radiotherapy with or without chemotherapy: a systematic literature review. Radiother Oncol, Amsterdam, mar 2013;66(3):253-62.

10.Sobrinho TJS, Castro VTN, Saraiva AM, Almeida DM, Tavares EA, Amorim E LC. Phenolic contente and antioxidant capacity of four Cnidoscolus species (Euphorbiaceae) used as ethnopharmacologicals in Caatinga, Brazil. Afr. J. Pharm. Pharmacol. 2011; 5,(20): 2310-2316.

11.Ferreira SB, Dantas IC. Catão RMR. Avaliação da atividade antimicrobiana do óleo essencial de sucupira (Pterodon emarginatus Vogel). Rev. bras. plantas med. 2014; 16(2): 225-230.

12. Innibi O, Lakhdar L, Bouziane A, Bensouda Y, Abougal R. Chlorhexidine alcohol base mouthrinse versus chlorhexidine formaldehyde base mouthrinse efficacy on plaque control: double blind, randomized clinical trials. Medicina Oral Patologia Oral y Cirurgia Bucal. 2013;18(1):135-139.

13.Cutrim ESM, Teles AM, Mouchrek AN, Mouchrek-Filho VE, Everton GO. valiação da Atividade Antimicrobiana e Antioxidante dos Óleos Essenciais e xtratos Hidroalcoólicos de Zingiber officinale (Gengibre) e Rosmarinus officinalis lecrim). Rev. Virtual Quim. 2019; 11(1): 60-81. 
14.Casagrande PP, Bietta ACM, Marenzoni ML, Scorza AV, Passamonti F. Insertion sequence IS256 in canine pyoderma isolates of Staphylococcus pseudintermedius associated with antibiotic resistance. Vet Microbiol. 2012; 15:157(4):376-82.

15.Silva AP, Schmidt CV, Agueda C, Maboni G, Rampelotto C, Schwab ML, Escobar TP, Amaral AS. Suscetibilidade antimicrobiana de Staphylococcus spp. isolados de cães com pioderma superficial. Pesquisa Veterinária Brasileira. 2019; 34(4): 355-36.

16. Solano MP, Bulgarelli PT, Santos CM, Mestriner SF, Júnior WN, Lago LPM, Bulgarelli AF. Utilização de serviços bucais na atenção primária: perspectivas dos usuários do sus de um município do sul do Brasil. Revista Ciência Plural. 2017;3(3):819. 